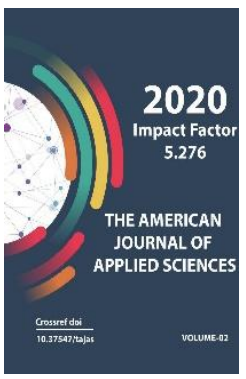

\title{
Systematic Analysis Of Two Helmint Fauna In Poultry
}

\author{
Dilorom Boxodirovna Fayzieva \\ Lecturer, Department Of Zoology, Termez State University Termez, Uzbekistan
}

Copyright: Original

content from this work

may be used under the

terms of the creative

commons attributes

4.0 licence.

\section{ABSTRACT}

The article describes a systematic analysis of the helminth fauna of some domestic birds (chicken, duck, goose). As a result of research, 38 species of helminths were identified, of which 9 species belong to trematodes, 12 species to cestodes, and 17 species to nematodes.

\section{KEYWORDS}

Poultry, helminth, extensiveness of damage, intensity of damage, cestode, trematode, nematode.

\section{INTRODUCTION}

Currently, great attention is paid to the poultry sector as the most profitable sector of agriculture. However, due to parasitic helminths and helminthiasis (ascaridosis, heterocytosis, echinostomatidosis, raetinosis, hymenolepidosis, aminodostomatidosis, capillariosis), the quality and quantity of poultry products decreases, and in most cases, especially young chickens die. A comprehensive study of bird helminths, ie the study of their species composition, distribution, seasonal dynamics and laws of formation of helminth fauna is one of the current issues in modern zoology, through which it is possible to develop effective methods to prevent and control these parasitic diseases. In Uzbekistan, helminths of poultry, including chickens, ducks and geese, have been studied by researchers such as MA Sultanov [5], HT Tangirov [6], VD Alimova [2], DA Azimov [1]. studied. MA Sultanov [5] conducted research on the systematics, fauna, ecology and biology of poultry and birds of hunting importance in Uzbekistan. HT Tangirov [6] studied the ecological monitoring of helminths of wild birds and poultry in Uzbekistan. VDAlimova [2] conducted a number of scientific studies on the 
comprehensive study of helminths and helminthiasis of domestic chickens in Uzbekistan. D.A. Azimov [1] determined the prevalence of helminthiasis in chickens, such as ascariasis, heterocytosis, syngamosis, prostagonimosis, scrabiniosis, rayitinosis, and developed measures to treat these diseases.

\section{RESEARCH MATERIAL AND METHODS}

The research was carried out on the basis of Academician KI Scriabin's "Complete helminthological cracking" [4] and N. Dubinina's "Parasitological examination of birds" [3], which are widely used in the study of bird helminths.

\section{RESEARCH RESULTS}

We systematically analyzed 38 species of helminths found during our research. Of these, 9 species belong to trematodes, 12 species to cestodes, and 17 species to nematodes. A systematic analysis of 32 species of helminths found in chickens revealed the presence of 9 species of trematodes, 10 species of cestodes, and 13 species of nematodes. A systematic analysis of 12 species of helminths found in ducks revealed the presence of 4 species of trematodes, 4 species of cestodes, and 4 species of nematodes. Systematic analysis of 4 species of helminths found in geese revealed the presence of 2 species of trematodes and 2 species of nematodes (picture-1).
The helminths found in chickens belong to 3 classes, 5 genera, 7 subspecies, 12 families, 18 genera and 32 species. The helminth species identified in chickens are divided into categories as follows: 8 species belonging to the subfamily Echinostomata from the class Trematodes, 1 species belonging to the subfamily Heterophyata, 10 species belonging to the family Cyclophyllida from the class Cestodes, 1 species belonging to the genus Rhabditida 1 species, 4 species belonging to the genus Trichocephalida.

The helminths found in ducks belong to 3 classes, 4 genera, 4 subspecies, 4 families, 9 genera and 12 species. The species of helminths identified in ducks are divided into categories as follows: 4 species from the class Echinostomata subspecies from the class Trematodes, 4 species from the class Cestlophyllida from the class Cestodes, 2 species from the genus Rhabditida from the class Nematodes, 2 species from the family Ascaridida.

The helminths found in geese belong to 2 classes, 3 genera, 3 subspecies, 3 families, 3 genera and 4 species. The helminth species identified in geese are divided into categories as follows: 2 species from the class Echinostomata subclass of the class Trematodes, 1 species belonging to the genus Ascaridida from the class nematodes, 1 species belonging to the genus Trichocephalida (picture-2). 


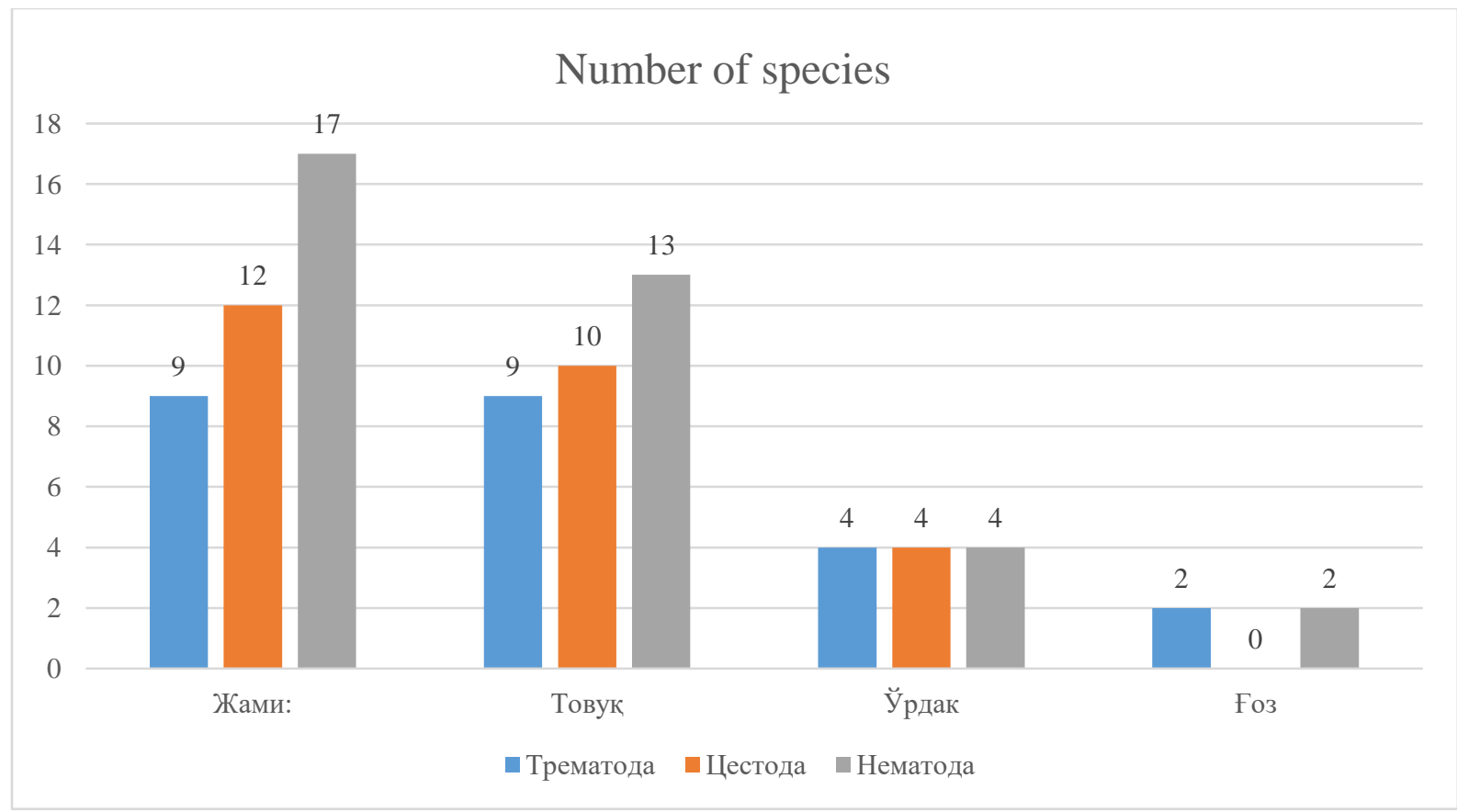

\section{1-picture. Number of helminths detected in chicken, duck and goose}

Of the 40 infected chickens, an average of IZ$7.3(E Z-8.5 \%)$ was detected in cestodes, an average of IZ-2.3 (EZ-2.4\%) in trematodes, and an average of IZ-12.3 (EZ-10.3\%) in nematodes. In chickens, the highest rate of helminth infestation was observed among nematodes (IZ-12.3, EZ-10.3\%). Infection with the lowest rate of helminths was observed among trematodes (IZ-2.3, EZ-2.4\%). Of the 5 infected ducks, an average of IZ-2.5 (EZ-12.5\%) was detected in cestodes, an average of IZ-2 (EZ$10 \%)$ in trematodes, and an average of $\mathrm{IZ}-2.75$ (EZ-12.5\%) in nematodes.

In ducks, the highest rate of helminth infestation was observed among nematodes (IZ-2.75, EZ-12.5\%). Infection with the lowest rate of helminths was observed among trematodes (IZ-2, EZ-10\%). Of the 3 affected geese, an average of IZ-1.5 (EZ-25\%) was detected in trematodes and an average of IZ-2 (EZ-25\%) in nematodes. Infection with cestodes was not observed in geese. It was found to be equally affected by trematodes and nematodes (Table-1).

Chickens were infected with an average of 7.3 cestodes, 2.3 trematodes, and 12.3 nematodes. Ducks were infected with an average of 2.5 cestodes, 2 trematodes, and 2.75 nematodes. In geese, an average of 1.5 trematodes and 2 nematodes were found to be infected, but no lesions with cestodes were observed in them (picture-3). 


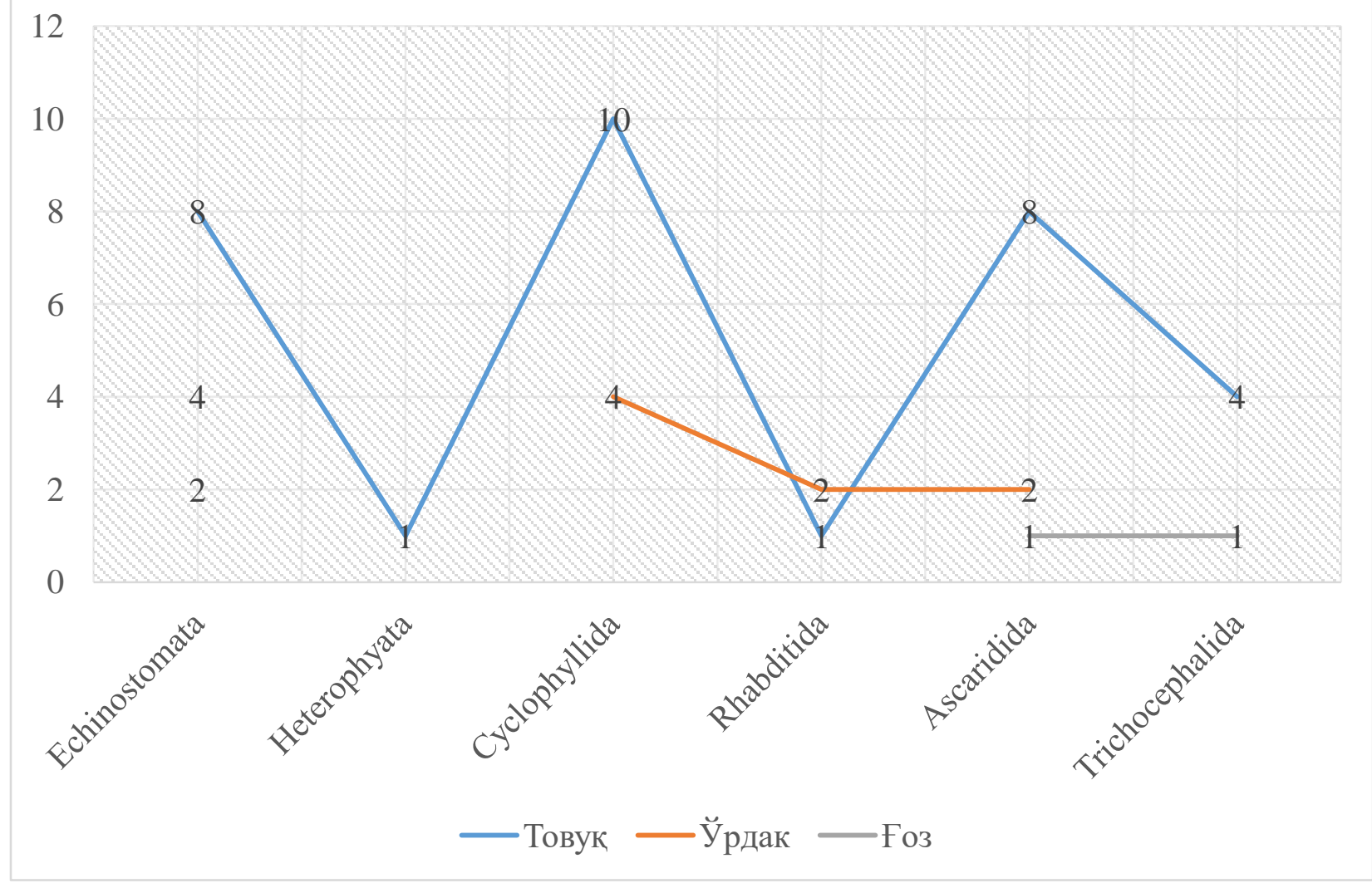

2-picture. Distribution of helminth species identified in chickens, ducks and geese by categories

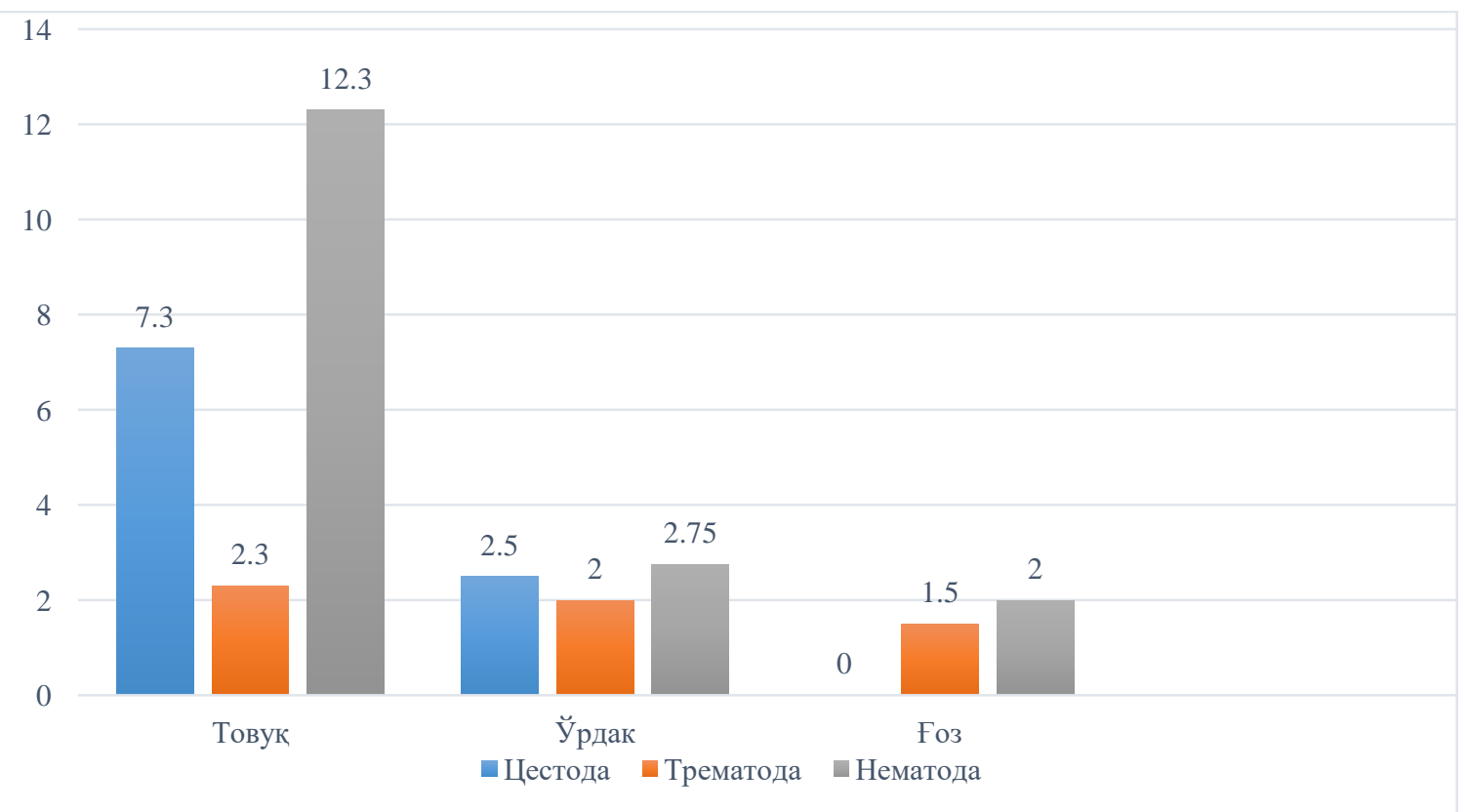

3-picture. Dynamics of helminth infestation of poultry 


\section{Separating from the birds inspected during 2017-2019 cross-sectional distribution of the}

\section{obtained helminths Table-1}

\begin{tabular}{|c|c|c|c|c|c|c|c|c|c|}
\hline \multirow[b]{3}{*}{$\begin{array}{l}\stackrel{0}{2} \\
\stackrel{2}{1} \\
\frac{1}{3} \\
0 \\
0\end{array}$} & \multirow{3}{*}{ 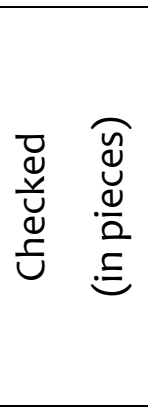 } & \multicolumn{8}{|c|}{ Infestation with helminths at the intersection of classes } \\
\hline & & \multirow{2}{*}{ 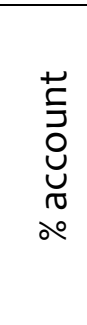 } & \multirow{2}{*}{ 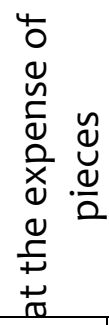 } & \multicolumn{2}{|c|}{ Cestodes } & \multicolumn{2}{|c|}{ Trematodes } & \multicolumn{2}{|c|}{ Trematodes } \\
\hline & & & & வீ & $\frac{\mathscr{U}}{\mathscr{\alpha}}$ & வீ & $\frac{\mathscr{U}}{\mathscr{U}}$ & ×ீ & $\begin{array}{l}\stackrel{y}{u} \\
\frac{\mathscr{U}}{\alpha}\end{array}$ \\
\hline 1 & 2 & 3 & 4 & 5 & 6 & 7 & 8 & 9 & 10 \\
\hline Chicken & 60 & 67 & 40 & 8,5 & 7,3 & 2,4 & 2,3 & 10,3 & 12,3 \\
\hline Duck & 10 & 50 & 5 & 12,5 & 2,5 & 10 & 2 & 12,5 & 2,75 \\
\hline Goose & 4 & 75 & 3 & - & - & 25 & 1,5 & 25 & 2 \\
\hline Total: & 74 & 192 & 48 & 21 & 9,8 & 37,4 & 5,8 & 47,8 & 17,05 \\
\hline
\end{tabular}

An analysis of our research shows that parasitic helminths are common in poultry and affect the development of poultry to varying degrees. Therefore, the development of species composition, systematics, distribution and methods of control of parasitic species of poultry is of great scientific and practical importance.

\section{REFERENCES}

1. Azimov D.A. Reconstruction of the trematode system of the suborder Schistosomatata Skrjabin et Schulz. 1937 // Zool.j. - 1970. - T.69. Issue 8. S. 1126-1131.

2. Alimova V.D. Helminthiasis of chickens and the development of measures to combat them in the conditions of Uzbekistan: Author's abstract. Cand. diss... . - Samarkand. - 1967.S. 218.

3. Dubinina M.N. Parasitological research of birds // Methods of parasitological research. - L .: Science. - Issue. 4.1971 - S. 3-139.
4. Skryabin K.I. The method of complete helminthological dissection of vertebrates, including humans. - Moscow. 1928 .- 45s.

5. Sultonov M.A. Helminths of birds of Uzbekistan // Monograph. -Toshkent. 1963.S. 465

6. 6. Tangirov Kh.T. Ecological monitoring of helminths of common species of wild and domestic birds in Uzbekistan // Author. Cand. diss .... - Tashkent. - 1993.S. 26 